\title{
6-Methoxy-3,3',3'-trimethylspiro[2H-1-benzopyran-2,1'[2]oxaindan]: Separation of Enantiomers, Circular Dichroism Measurements and Determination of the Absolute Configuration
}

\author{
Elena N. Voloshina, Yuekui Wang, Nikolai A. Voloshin ${ }^{\text {a }}$, Gerhard Raabe, \\ Hans-Joachim Gais, and Jörg Fleischhauer
Institut für Organische Chemie, Rheinisch-Westfälische Technische Hochschule Aachen, Prof.-Pirlet-Strasse, 1, D-52074 Aachen
a Institute of Physical and Organic Chemistry, Rostov State University, 344090 Rostov on Don, Russia

Reprint requests to Prof. J. F.; E-mail: Joerg.Fleischhauer@thc.rwth-aachen.de; Fax: +49(0)241/8092385.

Z. Naturforsch. 58a, 443 - 450 (2003); received June 7, 2003

The enantiomers of 6-methoxy-3,3',3'-trimethylspiro[2H-1-benzopyran-2,1'[2]oxaindan] were separated with the high-pressure liquid chromatography method. Their optical properties were studied experimentally and by quantum-chemical calculations. The absolute configurations of the compounds were determined by comparison of the measured and calculated CD spectra.

Key words: Spiropyrans; Circular Dichroism; TDDFT Calculations.

\section{Introduction}

Spiropyrans represent a class of organic photochroms [1-3]. The discovery of the photochromic reaction of spiropyrans by Fischer and Hirshberg in 1952 [4], and Hirshberg's idea of using this phenomenon for a photochemically erasable memory [5] initiated active research on photochromic spiropyrans. Based on their reversible colour and other changes in physical and chemical properties, these photoresponsive materials have now found many applications: self-developing photography, displays, optical filters, lenses of variable optical density, including sun glasses, optical recording media, etc. [1,6-10]. The photochromic (and also thermochromic) behavior of these compounds is due to the interconversion between the colourless closed spiropyran and the opened merocyanine-like dye (Scheme 1). Owing to the presence of the stereogenic $\mathrm{C}_{\text {spiro }}$ atom, the spiropyran molecules are chiral.

An enantiomerically pure, optically active spiropyran could be the object of several interesting experiments $[3,8,11,12]$, but laboratory procedures normally give a 1:1 mixture of both enantiomers. Successful attempts to separate the spiropyran enantiomers have already been undertaken by Mannschreck and coworkers [12-14], but the absolute configuration of the

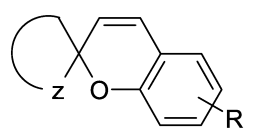

closed spirocyclic form Scheme 1.

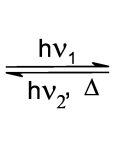
structure

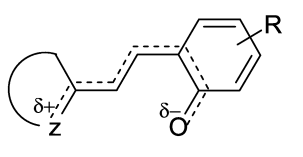

opened merocyanine-like stereoisomers has not been determined and still remains unknown. In this paper, we describe the separation of the enantiomers of 6-methoxy-3,3',3'-trimethylspiro[2H-1-benzopyran-2,1'[2] oxaindan] (1). We then measured the UV and CD spectra of both enantiomers and tried to determine the absolute configuration by comparison of the experimental CD spectra with the calculated ones.

\section{Results and Discussion}

Separation of the enantiomers and their optical properties. The enantiomers of 1 (Fig.1) were separated with the high-pressure liquid chromatography (HPLC) method [12].

The experimental CD spectrum of one of the enantiomers of $\mathbf{1}$, recorded in $\mathrm{MeOH}$, is shown in Figure 2. The Cotton effects at wavelengths $>$ ca. $250 \mathrm{~nm}$ are very broad and relatively weak while those below this value are not only much stronger but also signifi- 
Table 1. Experimental $\left(\lambda_{\max , \text { exp }}, \varepsilon_{\max , \exp }\right)$ and calculated $\left(\lambda_{\text {max.cal }}, \varepsilon_{\text {max.cal }}\right)$ UV spectra of spiropyran 1 in $\mathrm{MeOH}$. $\lambda_{\max }$ in $\mathrm{nm}, \varepsilon_{\max }$ in $1 \cdot \mathrm{cm}^{-1} \cdot \mathrm{mol}^{-1}$.

\begin{tabular}{ccrcr}
\hline No. & $\lambda_{\text {max }, \exp }$ & $\varepsilon_{\text {max }, \exp }$ & $\lambda_{\text {max }, \text { cal }}$ & $\varepsilon_{\text {max,cal }}$ \\
\hline 1 & 316 & 3326 & 351.9 & 3257 \\
2 & 256 & 7756 & 264.3 & 18468 \\
3 & 228 & 23441 & 216.7 & 29351 \\
4 & 211 & 25239 & 192.7 & 31935 \\
\hline
\end{tabular}

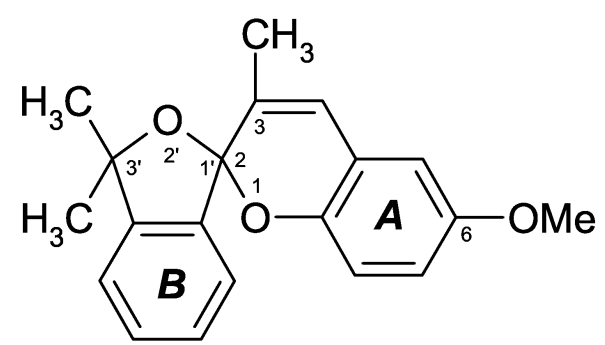

Fig. 1. 6-Methoxy-3,3',3'-trimethylspiro[2H-1-benzopyran-2,1'[2] oxaindan] $\mathbf{1}$.

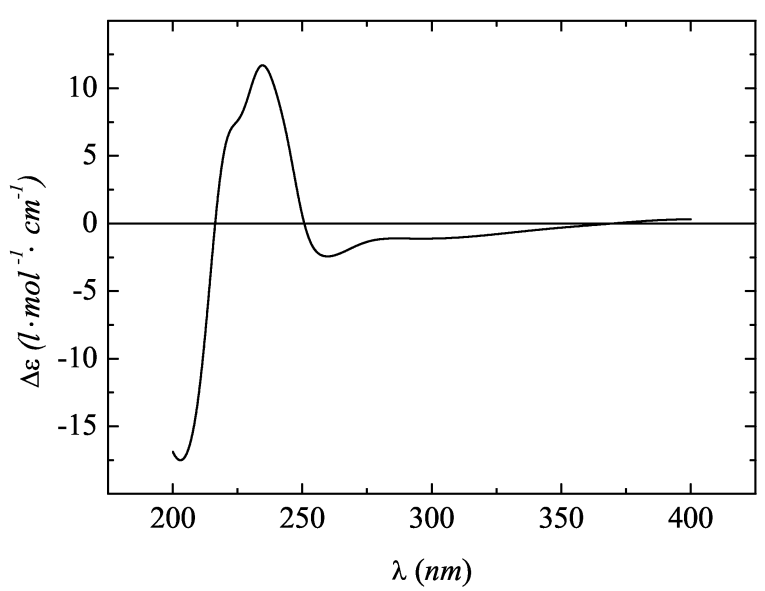

Fig. 2. Experimental CD spectrum of one of the enantiomers of 1 recorded in $\mathrm{MeOH}$.

cantly sharper. The noticeable CD peaks appear at the wavelengths $\lambda=398.0 \mathrm{~nm}(+0.30), 296.2 \mathrm{~nm}(-1.12)$, $286.4 \mathrm{~nm}(-1.10), 259.7 \mathrm{~nm}(-2.43), 234.6 \mathrm{~nm}$ $(+11.7)$, and $202.9 \mathrm{~nm}(-17.5)$. In addition, a shoulder is observed at about $225 \mathrm{~nm}(\sim 7.5)$. The numbers in parentheses are the corresponding values of $\Delta \varepsilon$ in $1 \cdot \mathrm{mol}^{-1} \cdot \mathrm{cm}^{-1}$.

The experimental and calculated UV spectra of the studied spiropyran are given in Figure 3. Measured and calculated values of $\lambda_{\max }$ and $\varepsilon_{\max }$ are listed in Table $1^{\text {a) }}$.

a) The first absorption band in the UV spectrum has been observed and calculated at 316 and $351.9 \mathrm{~nm}$, respectively. Compared with the other bands of the spectrum, this absorption is relatively weak.

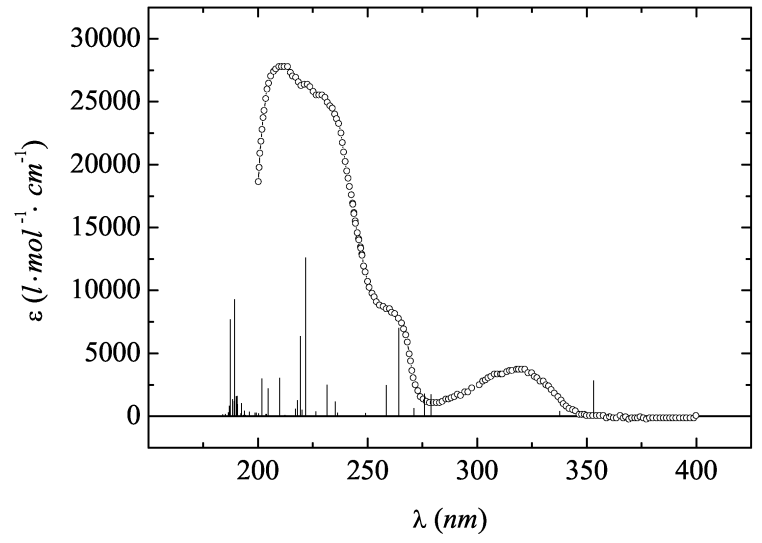

(a)

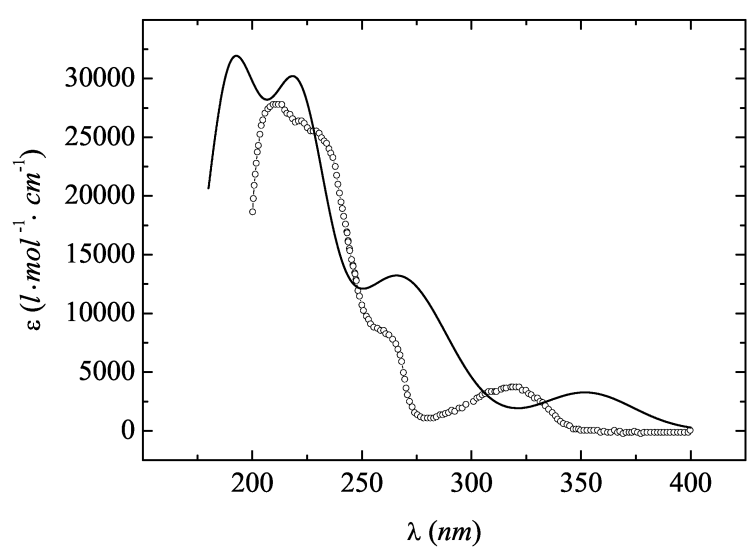

(b)

Fig. 3. (a) Experimental UV spectrum of the spiropyran 1 (in $\mathrm{MeOH}$ ). The bars are the calculated $\varepsilon_{\max }$. (b) The experimental UV spectrum of $\mathbf{1}$ (open circles) in comparison with its calculated counterpart (solid line).

Quantum-chemical calculations. The calculations have been performed for the arbitrarily chosen $R$-en-

According to our calculations it gets most of its intensity from the $\mathrm{HOMO} \rightarrow$ LUMO transition at $353.1 \mathrm{~nm}$ ( $c f$. Table 2). While a shoulder has been observed at $\lambda=256 \mathrm{~nm}$, we calculate a relatively sharp absorption band at $264.3 \mathrm{~nm}$, involving excitations within the part of the molecule containing ring A $\left(\Psi_{82} \rightarrow \Psi_{86}, \Psi_{81} \rightarrow \Psi_{83}\right)$ as well as charge transfer from B to A $\left(\Psi_{78} \rightarrow \Psi_{83}\right)$. Another transition, calculated at $258.6 \mathrm{~nm}\left(\Psi_{78} \rightarrow \Psi_{83}\right)$, will also contribute significantly to this absorption band. The strongest aborptions caused by three or more overlapping bands have been observed between 250 and $200 \mathrm{~nm}$ while our calculations predict intense transitions at 221.7 and $219.3 \mathrm{~nm}$ as well as at 189.3 and $187.4 \mathrm{~nm}$, respectively. 


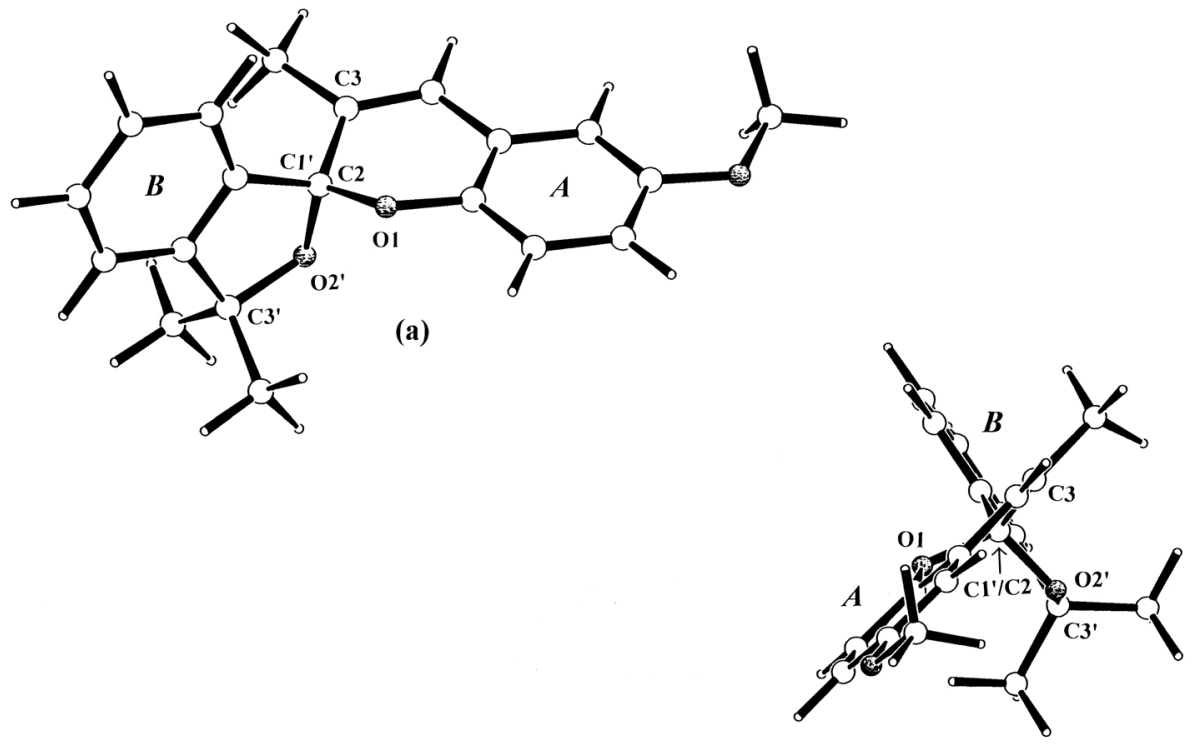

(b)
Fig. 4. Two perspective views (SCHAKAL plots [23]) of the structure of the $R$-isomer of spiropyran 1 calculated at the TZVP/B-P86 level of DFT. The structures optimized in the gas phase and in presence of the solvent are visually indistinguishable. While (a) gives a general view of the molecule (b) shows the relative orientation of the two planes containing the rings $\mathrm{A}$ and $\mathrm{B}$, respectively. antiomer of spiropyran $\mathbf{1}$. The coordinates used in the CD calculation have been obtained by geometry optimization of a structure based on standard bond lengths and bond angles [15] with the density functional theory $(\text { DFT })^{\mathrm{b})}$. All DFT calculations were performed using the TURBOMOLE [16] set of programs. In these calculations we used the B-P86 combination of exchange and correlation functionals [17] and a triple- $\zeta$ valence basis set, augmented by a shell of polarization functions (TZVP). The solvent effect $\left(\varepsilon_{\mathrm{CH}_{3} \mathrm{OH}}=32.63\right)$ has been taken into account by an electrostatic continuum model (COSMO, conductor-like screen model $[16,18])$. Two perspective views of the optimized spatial structure of the $R$-spiropyran are shown in Figure 4.

The UV and CD spectra have been calculated with the time-dependent density functional theory (TDDFT)[19] employing the structure optimized at the DFT level (Figures $3 b$ and 5). For the calculation of the rotational strengths the origin-independent dipole velocity approximation has been used [20].

Omitting the methyl and methoxy substituents compound 1 can approximately be described as consisting of two planes which intersect at an angle of $81.3^{\circ}$ and share the spiro carbon atom. Each of these planes contains one of the aromatic rings $\mathrm{A}$ and $\mathrm{B}$, respectively

\footnotetext{
b) The calculated dipole moments of the molecule obtained in the gas phase and in presence of the solvent are 2.13 and $3.43 D$, respectively.
}

(Figure 1). The symmetry of the molecule is $C_{1}$ and, therefore, a strict division of the molecular orbitals into $\pi$ - and $\sigma$-orbitals is not possible. However, using local symmetry we call such orbitals $\sigma$ - and $\sigma^{*}$ - or $\pi$ - and $\pi^{*}$-MOs which are symmetric or antisymmetric with respect to one of the two planes mentioned above. The Kohn-Sham orbitals (KSOs) $\Psi_{74}-\Psi_{90}$ are shown in Figure 6 . The corresponding eigenvalues of the energy cover the range between approximately -8 and $1 \mathrm{eV}$, and it can be seen that each of the $\pi$ - and $\pi^{*}$-MOs is widely localized in one of the planes containing either ring $\mathrm{A}$ or $\mathrm{B}$.

Our TDDFT calculations in presence of $\mathrm{MeOH}$ predict 50 transitions in the range between $180-400 \mathrm{~nm}$. The relevant configurations for these states are listed in Table 2 together with the calculated oscillator and rotational strengths at the absorption maxima. In addition we list the angles $\theta$ between the electric and the magnetic transition dipole moments. In cases where this angle is close to $90^{\circ}$ the sign of the corresponding Cotton effect is very sensitive even to small changes of the molecular structure.

For reasons of comparison we list the corresponding data for the 50 lowest transitions calculated for the gasphase in Table 3. All transitions are solvent-dependent as far as the excitation energies and the contributions of the leading configurations are concerned. Under the influence of the solvent the excitation wavelengths are 


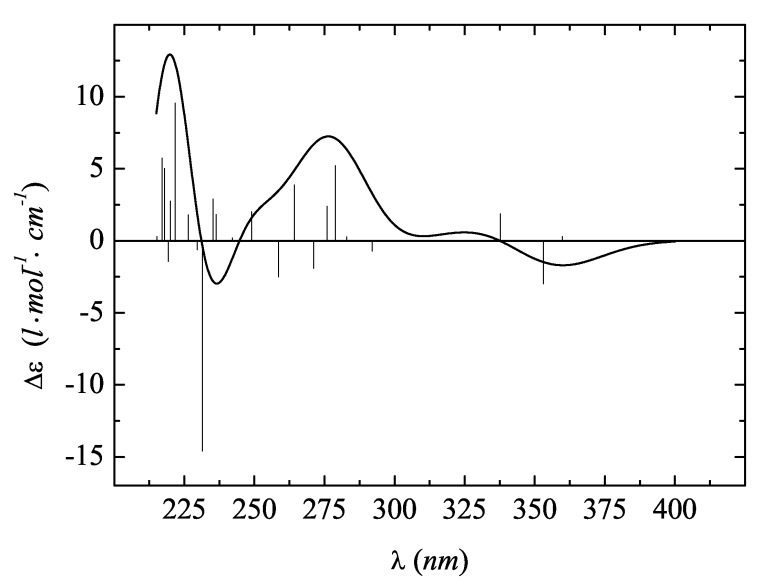

(a)

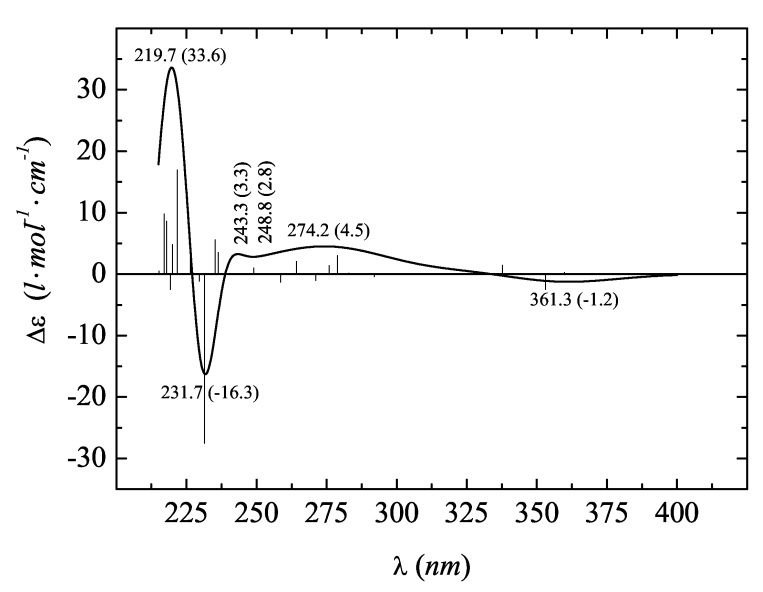

(b)

Fig. 5. CD spectrum of the spiropyran 1 ( $R$-isomer) calculated at the TZVP/B-P86 level of TDDFT. The bars are the $\Delta \varepsilon_{\text {max,cal }}$ of the generating Gaussian curves. Spectrum (5a) has been obtained using an empirical relationship between the half bandwidth $(\Gamma)$ and the transition wavelength (see text and [22]). Spectrum (5b) has been generated using the constant values of $\Gamma=7$ below and $\Gamma=30$ above $\lambda=240 \mathrm{~nm}$ (numerical values of $\Delta \varepsilon_{\max , \text { cal }}$ in parentheses).

shifted to the blue. The strongest shift of about $24 \mathrm{~nm}$ has been calculated for the energetically lowest transition $\left(\pi \rightarrow \pi^{*}\right)$, which in presence of $\mathrm{MeOH}$ has been predicted to occur at $\lambda=359.8 \mathrm{~nm}$. It occurs from the HOMO $\left(\Psi_{82}\right)$ to $\Psi_{84}$ and has a small positive rota- tional strength. While $\Psi_{82}$ has its largest coefficients at the aromatic ring $\mathrm{A}$ and the neighbouring olefinic double bond, $\Psi_{84}$ is predominantly located at benzene ring B ( $c f$. Figure 6). This excitation can therefore be described as an intramolecular charge transfer transition from ring A to ring $\mathrm{B}$. The second excitation, calculated at $\lambda=353.1 \mathrm{~nm}$ with a much stronger negative rotational strength, occurs from the HOMO to the LUMO $\left(\Psi_{83}\right)$ and is also a $\pi \rightarrow \pi^{*}$ transition. However, different from the first one, in this case both KSOs are located in the same plane and have their largest coefficients at the aromatic ring $\mathrm{A}$ and the adjacent olefinic double bond. The third transition calculated at $337.7 \mathrm{~nm}\left(\Psi_{82} \rightarrow \Psi_{85}\right)$, can again be described as an intramolecular charge transfer of the $\pi \rightarrow \pi^{*}$ type. The excitation with the most negative rotational strength $\left(-33.90 \times 10^{-40} \mathrm{erg} \cdot \mathrm{cm}^{3}\right)$ above $200 \mathrm{~nm}$ has been calculated at $231.4 \mathrm{~nm}$. It is located in the ring A and is the energetically lowest transition which involves an excitation from a $\sigma$ - to a $\pi^{*}$-MO $\left(\Psi_{76} \rightarrow \Psi_{83}\right)$. In the same region the strongest positive rotational strength $\left(21.76 \times 10^{-40} \mathrm{erg} \cdot \mathrm{cm}^{3}\right)$ has been calculated for a transition at $221.7 \mathrm{~nm}$. It contains almost equal contributions of a transition from ring A to B $\left(\Psi_{77} \rightarrow \Psi_{85}\right)$ and another one located in A $\left(\Psi_{82} \rightarrow \Psi_{87}\right)$.

The calculated CD curves (Figure 5) have been obtained as a sum of Gaussians, each of which has been centered at the wavelength of the corresponding transition and multiplied with its rotational strength [21]. Two different approaches have been used to obtain the half bandwidths $(\Gamma)$ of the Gaussians. First we used the empirical formula $\Gamma=\kappa \cdot \lambda_{\text {cal }}^{1.5}$, where $\lambda_{\text {cal }}$ is the calculated transition wavelength and the parameter $\kappa$ has been assumed to be $0.00375^{\mathrm{c})}$ [22]. The resulting CD spectrum is shown in Figure 5a. According to the shape of the Cotton effects the experimental CD curve in Figure 2 might roughly be divided into two parts: above $\sim 250 \mathrm{~nm}$ the Cotton effects are consistently very broad while those at wavelengths below this value are much sharper. In a second approach we therefore used two different bandwidths to model the short and the long wavelengths part of the CD curve. Thus, the Gaussians have been generated using values of $\Gamma=7$ for $\lambda<240 \mathrm{~nm}$ and $\Gamma=30$ for $\lambda \geq 240 \mathrm{~nm}$ at $\Delta \varepsilon_{\text {max,cal }} / e$. In both cases the empirical relationship $\Delta \varepsilon_{\text {max,cal }}=2.28 \cdot \lambda_{\text {max,cal }} \cdot \Gamma^{-1} \cdot R(R$ is the rotational strength) has been used to calculate $\Delta \varepsilon_{\text {max,cal }}$.

\footnotetext{
${ }^{\text {c) }}$ This formula yields values of $\Gamma$ from 12.2 to 30.0 between 220 and $400 \mathrm{~nm}$.
} 

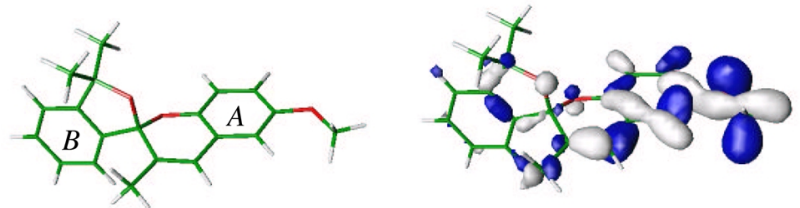

74th KSO, $\sigma$

$(-8.01 \mathrm{eV})$

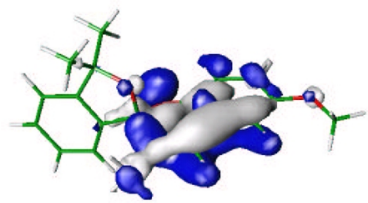

76th KSO, $\sigma$

$(-7.47 \mathrm{eV})$

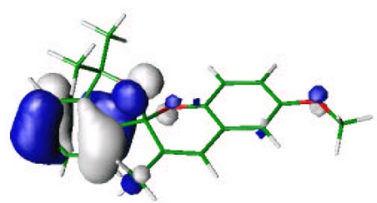

79th KSO, $\pi_{B}$

$(-6.52 \mathrm{eV})$

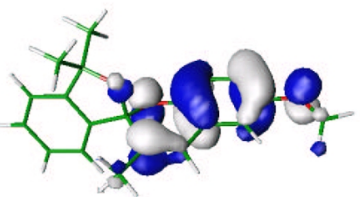

82th KSO, $\pi_{A}$

$(-5.04 \mathrm{eV})$

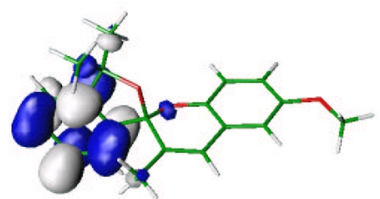

85 th KSO, $\pi_{B}^{*}$

$(-1.39 \mathrm{eV})$

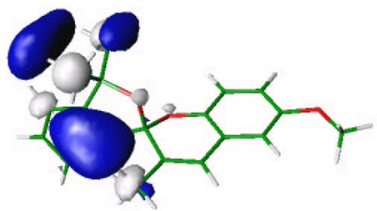

88 th $\mathrm{KSO}, \sigma^{*}$

$(0.66 \mathrm{eV})$

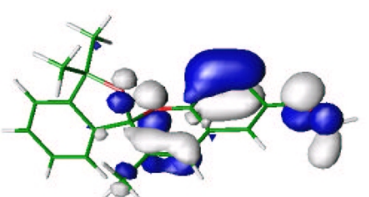

77 th $\mathrm{KSO}, \pi_{A}$

$(-7.01 \mathrm{eV})$

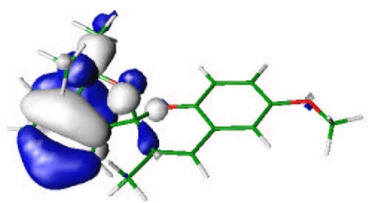

80 th $\mathrm{KSO}, \pi_{B}$

$(-6.37 \mathrm{eV})$

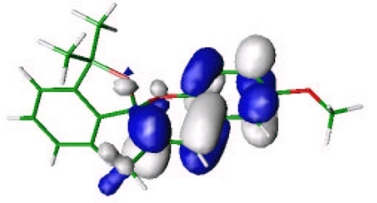

83th KSO, $\pi_{A}^{*}$

$(-2.00 \mathrm{eV})$

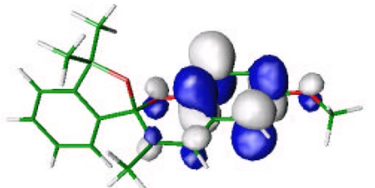

86th KSO, $\pi_{A}^{*}$

$(-0.90 \mathrm{eV})$

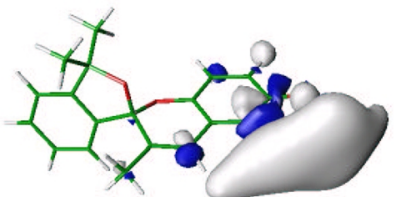

89th KSO, $\sigma^{*}$

$(1.04 \mathrm{eV})$

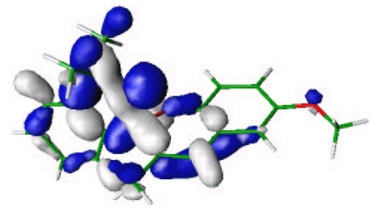

75th KSO, $\sigma$

$(-7.81 \mathrm{eV})$

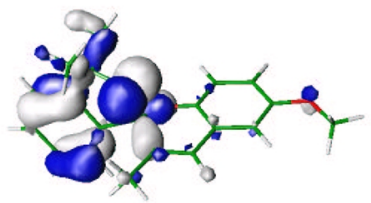

78th KSO, $\pi_{B}$

(-6.71 eV)

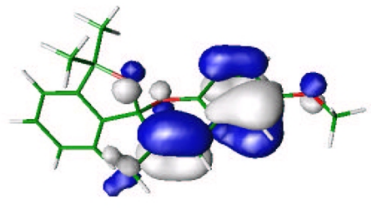

81th KSO, $\pi_{A}$

$(-5.84 \mathrm{eV})$

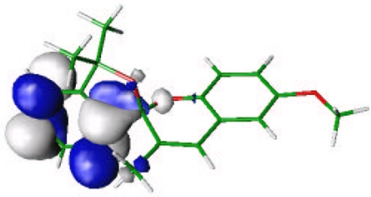

84th KSO, $\pi_{B}^{*}$

$(-1.61 \mathrm{eV})$

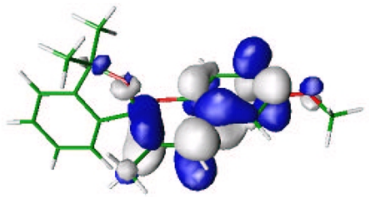

87 th KSO, $\pi_{A}^{*}$

$(0.03 \mathrm{eV})$

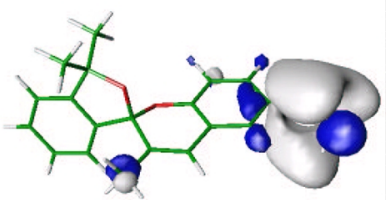

90th KSO, $\sigma^{*}$

$(1.12 \mathrm{eV})$
Fig. 6. Kohn-Sham orbitals $\Psi_{74}$ to $\Psi_{90}$ of the spiropyran $\mathbf{1}$. 
Table 2. The electronic configurations, oscillator and rotational strengths for the exited states of spiropyran $\mathbf{1}$ calculated in presence of MeOH. $\theta$ is the angle between the electric and the magnetic dipole moment.

\begin{tabular}{|c|c|c|c|c|c|}
\hline $\begin{array}{l}\text { Wavelength } \\
(\mathrm{nm})\end{array}$ & Transition & $\begin{array}{c}\text { Contribution } \\
(\%)\end{array}$ & $\begin{array}{c}\theta \\
\text { (degree) }\end{array}$ & $\begin{array}{l}\text { Oscillator } \\
\text { Strength }\end{array}$ & $\begin{array}{c}\text { Rotational Strength } \\
\left(\times 10^{-40} \mathrm{erg} \cdot \mathrm{cm}^{3}\right)\end{array}$ \\
\hline 359.8 & $82 \rightarrow 84$ & 97.7 & 82.8 & 0.0029 & 0.89 \\
\hline 353.1 & $82 \rightarrow 83$ & 83.6 & 92.9 & 0.0517 & -8.55 \\
\hline 337.7 & $82 \rightarrow 85$ & 94.9 & 68.5 & 0.0077 & 5.25 \\
\hline 292.0 & $81 \rightarrow 84$ & 99.5 & 135.6 & 0.0011 & -1.86 \\
\hline 282.9 & $80 \rightarrow 83$ & 99.0 & 67.4 & 0.0008 & 0.69 \\
\hline 278.9 & $81 \rightarrow 85$ & 70.0 & 81.8 & 0.0507 & 13.32 \\
\hline \multirow[t]{3}{*}{275.9} & $79 \rightarrow 83$ & 35.6 & 87.0 & 0.0539 & 6.07 \\
\hline & $81 \rightarrow 85$ & 26.9 & & & \\
\hline & $81 \rightarrow 83$ & 22.7 & & & \\
\hline \multirow[t]{2}{*}{271.1} & $79 \rightarrow 83$ & 53.2 & 92.6 & 0.0197 & -4.82 \\
\hline & $82 \rightarrow 86$ & 21.0 & & & \\
\hline \multirow{3}{*}{264.3} & $82 \rightarrow 86$ & 37.5 & 85.6 & 0.2299 & 9.61 \\
\hline & $81 \rightarrow 83$ & 20.3 & & & \\
\hline & $78 \rightarrow 83$ & 16.3 & & & \\
\hline 258.6 & $78 \rightarrow 83$ & 74.9 & 92.3 & 0.0847 & -6.18 \\
\hline \multirow[t]{2}{*}{249.1} & $80 \rightarrow 84$ & 63.5 & 72.1 & 0.0089 & 4.87 \\
\hline & $79 \rightarrow 85$ & 15.3 & & & \\
\hline \multirow[t]{3}{*}{242.1} & $78 \rightarrow 84$ & 40.2 & 73.0 & 0.0004 & 0.50 \\
\hline & $79 \rightarrow 85$ & 24.9 & & & \\
\hline & $79 \rightarrow 84$ & 22.5 & & & \\
\hline \multirow[t]{2}{*}{236.4} & $77 \rightarrow 83$ & 63.8 & 82.2 & 0.0058 & 4.29 \\
\hline & $78 \rightarrow 85$ & 8.4 & & & \\
\hline \multirow{2}{*}{235.2} & $78 \rightarrow 85$ & 50.8 & 75.2 & 0.0256 & 6.77 \\
\hline & $80 \rightarrow 85$ & 17.2 & & & \\
\hline \multirow[t]{2}{*}{231.4} & $81 \rightarrow 86$ & 62.8 & 102.3 & 0.0569 & -33.90 \\
\hline & $76 \rightarrow 83$ & 14.7 & & & \\
\hline 229.6 & $77 \rightarrow 84$ & 93.1 & 162.0 & 0.0003 & -1.46 \\
\hline 226.4 & $80 \rightarrow 86$ & 89.9 & 64.8 & 0.0084 & 4.13 \\
\hline \multirow[t]{2}{*}{221.7} & $77 \rightarrow 85$ & 37.7 & 80.1 & 0.3140 & 21.76 \\
\hline & $82 \rightarrow 87$ & 35.3 & & & \\
\hline \multirow[t]{2}{*}{220.0} & $79 \rightarrow 86$ & 61.8 & 61.9 & 0.0124 & 6.26 \\
\hline & $76 \rightarrow 83$ & 15.4 & & & \\
\hline \multirow[t]{2}{*}{219.3} & $77 \rightarrow 85$ & 42.3 & 92.0 & 0.1616 & -3.23 \\
\hline & $82 \rightarrow 87$ & 23.4 & & & \\
\hline \multirow[t]{3}{*}{217.9} & $76 \rightarrow 83$ & 37.1 & 77.0 & 0.0320 & 11.29 \\
\hline & $75 \rightarrow 83$ & 14.9 & & & \\
\hline & $79 \rightarrow 86$ & 12.0 & & & \\
\hline 217.1 & $82 \rightarrow 88$ & 90.0 & 43.4 & 0.0153 & 12.90 \\
\hline \multirow[t]{3}{*}{215.3} & $79 \rightarrow 84$ & 22.3 & 44.2 & 0.0012 & 0.66 \\
\hline & $76 \rightarrow 84$ & 20.5 & & & \\
\hline & $80 \rightarrow 85$ & 16.2 & & & \\
\hline
\end{tabular}

The resulting CD spectrum is shown in Figure 5b. The signs of the Cotton effects in Figs. $5 \mathrm{a}$ and $5 \mathrm{~b}$ and, therefore, the characteristics of both calculated spectra agree.

A comparison of the experimental and the calculated CD spectra in Figs. 2 and 5a,b shows that the signs of the Cotton effects in the theoretical spectrum calculated for $R \mathbf{- 1}$ are essentially opposite to the experimental ones. Thus, we conclude that the enantiomer investigated experimentally should have the $S$ configuration $^{\mathrm{d})}$.

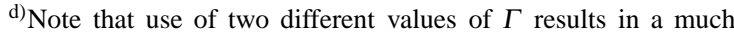
better agreement between the shapes of the calculated and measured CD curves than use of the empirical function $\Gamma=\kappa \cdot \lambda_{\text {cal }}^{1.5}$.
}

\begin{tabular}{|c|c|c|c|c|c|}
\hline $\begin{array}{l}\text { Wavelength } \\
(\mathrm{nm})\end{array}$ & Transition & $\begin{array}{c}\text { Contribution } \\
(\%)\end{array}$ & $\begin{array}{c}\theta \\
\text { (degree) }\end{array}$ & $\begin{array}{l}\text { Oscillator } \\
\text { Strength }\end{array}$ & $\begin{array}{c}\text { Rotational Strength } \\
\left(\times 10^{-40} \mathrm{erg} \cdot \mathrm{cm}^{3}\right)\end{array}$ \\
\hline 212.3 & $78 \rightarrow 86$ & 77.1 & 65.8 & 0.0024 & 2.71 \\
\hline \multirow[t]{2}{*}{209.9} & $76 \rightarrow 84$ & 65.2 & 50.3 & 0.0163 & 13.80 \\
\hline & $80 \rightarrow 85$ & 10.8 & & & \\
\hline \multirow[t]{2}{*}{209.8} & $75 \rightarrow 83$ & 51.0 & 107.6 & 0.0842 & -32.99 \\
\hline & $78 \rightarrow 86$ & 10.9 & & & \\
\hline 204.6 & $74 \rightarrow 83$ & 73.5 & 123.9 & 0.0646 & -13.00 \\
\hline 203.8 & $76 \rightarrow 85$ & 84.6 & 69.7 & 0.0042 & 3.08 \\
\hline 203.5 & $82 \rightarrow 89$ & 91.5 & 85.0 & 0.0044 & 1.39 \\
\hline 201.7 & $73 \rightarrow 83$ & 70.6 & 91.1 & 0.0893 & -0.57 \\
\hline 200.2 & $82 \rightarrow 90$ & 89.7 & 53.1 & 0.0065 & 6.00 \\
\hline 199.1 & $75 \rightarrow 84$ & 97.1 & 139.1 & 0.0076 & -4.65 \\
\hline 198.6 & $82 \rightarrow 91$ & 97.3 & 131.0 & 0.0082 & -11.53 \\
\hline 196.0 & $82 \rightarrow 92$ & 96.3 & 48.0 & 0.0108 & 6.93 \\
\hline 194.2 & $72 \rightarrow 83$ & 72.8 & 135.3 & 0.0027 & -2.54 \\
\hline \multirow[t]{2}{*}{193.7} & $74 \rightarrow 84$ & 45.3 & 80.4 & 0.0132 & 7.81 \\
\hline & $80 \rightarrow 87$ & 41.4 & & & \\
\hline \multirow[t]{2}{*}{193.4} & $80 \rightarrow 87$ & 49.3 & 106.0 & 0.0027 & -1.36 \\
\hline & $74 \rightarrow 84$ & 48.4 & & & \\
\hline 192.5 & $75 \rightarrow 85$ & 69.5 & 102.1 & 0.0336 & -23.4 \\
\hline 192.2 & $82 \rightarrow 93$ & 85.9 & 85.6 & 0.0069 & 1.52 \\
\hline \multirow[t]{4}{*}{190.6} & $81 \rightarrow 88$ & 34.4 & 56.1 & 0.0316 & 47.31 \\
\hline & $77 \rightarrow 86$ & 15.3 & & & \\
\hline & $79 \rightarrow 87$ & 10.5 & & & \\
\hline & $76 \rightarrow 86$ & 10.3 & & & \\
\hline 190.5 & $81 \rightarrow 88$ & 59.6 & 87.2 & 0.0540 & 7.14 \\
\hline 190.1 & $73 \rightarrow 84$ & 61.1 & 104.3 & 0.0536 & -32.84 \\
\hline \multirow[t]{4}{*}{189.3} & $73 \rightarrow 84$ & 19.8 & 104.4 & 0.3172 & -150.23 \\
\hline & $79 \rightarrow 84$ & 16.5 & & & \\
\hline & $80 \rightarrow 85$ & 14.6 & & & \\
\hline & $77 \rightarrow 86$ & 10.5 & & & \\
\hline \multirow[t]{2}{*}{189.1} & $71 \rightarrow 83$ & 44.9 & 93.2 & 0.0403 & -4.63 \\
\hline & $79 \rightarrow 87$ & 37.1 & & & \\
\hline \multirow[t]{2}{*}{188.5} & $79 \rightarrow 87$ & 31.3 & 66.9 & 0.0461 & 33.75 \\
\hline & $71 \rightarrow 83$ & 28.8 & & & \\
\hline \multirow[t]{3}{*}{187.4} & $79 \rightarrow 85$ & 23.2 & 88.8 & 0.2695 & 7.15 \\
\hline & $80 \rightarrow 84$ & 15.7 & & & \\
\hline & $71 \rightarrow 83$ & 8.9 & & & \\
\hline 186.8 & $74 \rightarrow 85$ & 83.7 & 87.7 & 0.0282 & 3.53 \\
\hline 186.4 & $82 \rightarrow 94$ & 93.4 & 87.9 & 0.0101 & 1.54 \\
\hline 185.1 & $70 \rightarrow 83$ & 80.3 & 104.8 & 0.0053 & -5.81 \\
\hline 183.8 & $78 \rightarrow 87$ & 61.6 & 68.7 & 0.0043 & 7.03 \\
\hline
\end{tabular}

\section{Experimental Part}

High-pressure liquid chromatography was performed on a chiracel-OD coulumn with $n$-hexane/ ethanol $(v: v=89: 1$, column $200 \times 20 \mathrm{~mm}$, flow rate $6 \mathrm{ml} \cdot \mathrm{min}^{-1}$, pressure $11 \mathrm{bar}$ ) as eluent. The injected quantities of the racemates were in the range of $10 \mathrm{mg}$ in $1 \mathrm{ml}$ of eluent. For photomeric detection the absorption of the compound at $365 \mathrm{~nm}$ was used.

The CD spectra were measured using a Circular Dichroism spectrometer (AVIV Model 62DS) at room temperature in methanol.

\section{Acknowledgements}

The authors gratefully acknowledge financial support by the Deutsche Forschungsgemeinschaft and the Fonds der Chemischen Industrie. E. N. V. is thankful 
Table 3. The electronic configurations, calculated oscillator and rotational strengths for the exited states of spiropyran $\mathbf{1}$ in vacuum.

\begin{tabular}{|c|c|c|c|c|c|}
\hline $\begin{array}{l}\text { Wavelength } \\
(\mathrm{nm})\end{array}$ & Transition & $\begin{array}{c}\text { Contribution } \\
(\%)\end{array}$ & $\begin{array}{c}\theta \\
\text { (degree) }\end{array}$ & $\begin{array}{l}\text { Oscillator } \\
\text { Strength }\end{array}$ & $\begin{array}{c}\text { Rotational Strength } \\
\left(\times 10^{-40} \mathrm{erg} \cdot \mathrm{cm}^{3}\right)\end{array}$ \\
\hline 384.2 & $82 \rightarrow 84$ & 99.9 & 93.2 & 0.0022 & -0.18 \\
\hline \multirow[t]{3}{*}{364.5} & $83 \rightarrow 85$ & 58.6 & & 0.0166 & -10.04 \\
\hline & $82 \rightarrow 83$ & & 100.5 & & \\
\hline & $82 \rightarrow 83$ & 38.6 & & & \\
\hline \multirow[t]{2}{*}{351.9} & $82 \rightarrow 83$ & 51.2 & 85.9 & 0.0450 & 7.99 \\
\hline & $82 \rightarrow 85$ & 40.9 & & & \\
\hline 304.4 & $81 \rightarrow 84$ & 99.7 & 115.3 & 0.0011 & -1.21 \\
\hline 289.8 & $81 \rightarrow 85$ & 93.0 & 76.8 & 0.0146 & 4.52 \\
\hline \multirow[t]{3}{*}{276.2} & $81 \rightarrow 83$ & 37.1 & 85.7 & 0.0978 & 15.36 \\
\hline & $80 \rightarrow 83$ & 29.1 & & & \\
\hline & $82 \rightarrow 86$ & 19.5 & & & \\
\hline \multirow{2}{*}{273.1} & $80 \rightarrow 83$ & 64.6 & 93.5 & 0.0131 & -4.51 \\
\hline & $79 \rightarrow 83$ & 12.3 & & & \\
\hline \multirow[t]{2}{*}{266.0} & $79 \rightarrow 83$ & 49.8 & 70.4 & 0.0591 & 11.98 \\
\hline & $82 \rightarrow 86$ & 31.4 & & & \\
\hline \multirow[t]{4}{*}{262.5} & $79 \rightarrow 83$ & 28.2 & 92.7 & 0.2067 & -11.42 \\
\hline & $81 \rightarrow 83$ & 24.4 & & & \\
\hline & $82 \rightarrow 86$ & 14.3 & & & \\
\hline & $78 \rightarrow 83$ & 13.7 & & & \\
\hline \multirow[t]{2}{*}{257.4} & $78 \rightarrow 83$ & 56.5 & 100.9 & 0.0340 & -10.32 \\
\hline & $80 \rightarrow 84$ & 24.1 & & & \\
\hline \multirow[t]{2}{*}{254.9} & $80 \rightarrow 84$ & 46.1 & 58.4 & 0.0086 & 9.08 \\
\hline & $78 \rightarrow 83$ & 27.2 & & & \\
\hline \multirow[t]{2}{*}{247.2} & $80 \rightarrow 85$ & 40.5 & 60.8 & 0.0057 & 6.82 \\
\hline & $79 \rightarrow 85$ & 30.5 & & & \\
\hline \multirow[t]{2}{*}{241.4} & $78 \rightarrow 85$ & 42.7 & 67.4 & 0.0153 & 6.96 \\
\hline & $79 \rightarrow 84$ & 24.6 & & & \\
\hline 238.1 & $77 \rightarrow 84$ & 83.4 & 59.9 & 0.0007 & 1.33 \\
\hline 237.1 & $77 \rightarrow 83$ & 67.5 & 110.6 & 0.0066 & -9.20 \\
\hline 234.8 & $82 \rightarrow 88$ & 94.3 & 145.0 & 0.0006 & -2.56 \\
\hline \multirow[t]{2}{*}{229.8} & $81 \rightarrow 86$ & 58.0 & 93.5 & 0.0484 & -7.19 \\
\hline & $76 \rightarrow 83$ & 14.1 & & & \\
\hline 227.9 & $77 \rightarrow 85$ & 77.6 & 90.6 & 0.0649 & -0.29 \\
\hline 224.3 & $82 \rightarrow 89$ & 99.6 & 84.1 & 0.0068 & 2.14 \\
\hline 221.9 & $82 \rightarrow 87$ & 59.2 & 85.3 & 0.4579 & 24.54 \\
\hline \multirow[t]{2}{*}{219.6} & $80 \rightarrow 86$ & 52.4 & 150.6 & 0.0048 & -2.43 \\
\hline & $76 \rightarrow 84$ & 15.9 & & & \\
\hline \multirow[t]{2}{*}{218.3} & $76 \rightarrow 84$ & 38.6 & 55.6 & 0.0031 & 5.33 \\
\hline & $80 \rightarrow 86$ & 23.6 & & & \\
\hline \multirow[t]{3}{*}{217.3} & $76 \rightarrow 83$ & 39.9 & 96.1 & 0.0284 & -6.64 \\
\hline & $75 \rightarrow 83$ & 12.7 & & & \\
\hline & $76 \rightarrow 84$ & 12.0 & & & \\
\hline 215.0 & $82 \rightarrow 90$ & 97.8 & 38.9 & 0.0049 & 8.57 \\
\hline 213.2 & $79 \rightarrow 86$ & 75.4 & 21.5 & 0.0029 & 11.03 \\
\hline \multirow[t]{4}{*}{213.1} & $76 \rightarrow 84$ & 24.2 & 72.3 & 0.0044 & 3.51 \\
\hline & $82 \rightarrow 91$ & 17.4 & & & \\
\hline & $79 \rightarrow 85$ & 14.1 & & & \\
\hline & $78 \rightarrow 84$ & 9.8 & & & \\
\hline
\end{tabular}

for a fellowship granted by the Graduierten Kolleg "Methoden in der Asymmetrischen Synthese". We fur-

[1] J.C. Crano, R. Guglielmetty (eds.), Organic Photochromic and Thermochromic Compounds, Plenum Publishers, New York 1999, Vol. 1 and 2.

[2] H. Dürr, H. Bouas-Laurent (eds.), Photochromism. Molecules and Systems. Elsevier, Amsterdam 1990.

[3] R.C. Bertelson, in Techniques of Chemistry. Vol. 3, Photochromism. G.H. Brown (ed.), Photochromic Processes Involving Heterolytic Cleavage. WileyInterscience, New York 1971.

\begin{tabular}{|c|c|c|c|c|c|}
\hline $\begin{array}{l}\text { Wavelength } \\
\text { (nm) }\end{array}$ & Transition & $\begin{array}{c}\text { Contribution } \\
(\%)\end{array}$ & $\begin{array}{c}\theta \\
\text { (degree) }\end{array}$ & $\begin{array}{l}\text { Oscillator } \\
\text { Strength }\end{array}$ & $\begin{array}{c}\text { Rotational Strength } \\
\left(\times 10^{-40} \mathrm{erg} \cdot \mathrm{cm}^{3}\right)\end{array}$ \\
\hline 212.3 & $82 \rightarrow 91$ & 72.0 & 82.7 & 0.0071 & 0.55 \\
\hline \multirow[t]{2}{*}{209.3} & $76 \rightarrow 85$ & 58.1 & 106.3 & 0.0107 & -4.53 \\
\hline & $78 \rightarrow 86$ & 31.7 & & & \\
\hline \multirow[t]{3}{*}{208.4} & $78 \rightarrow 86$ & 45.0 & 86.6 & 0.0529 & 2.05 \\
\hline & $75 \rightarrow 83$ & 22.6 & & & \\
\hline & $76 \rightarrow 85$ & 14.6 & & & \\
\hline \multirow[t]{4}{*}{206.8} & $82 \rightarrow 92$ & 30.8 & 94.3 & 0.0496 & -2.96 \\
\hline & $75 \rightarrow 83$ & 21.1 & & & \\
\hline & $78 \rightarrow 86$ & 13.6 & & & \\
\hline & $76 \rightarrow 85$ & 10.6 & & & \\
\hline 206.7 & $82 \rightarrow 92$ & 67.9 & 104.0 & 0.0331 & -11.7 \\
\hline 203.5 & $75 \rightarrow 84$ & 95.9 & 160.7 & 0.0042 & -5.11 \\
\hline 202.8 & $74 \rightarrow 83$ & 74.3 & 108.8 & 0.0533 & -7.36 \\
\hline 202.4 & $81 \rightarrow 88$ & 91.0 & 124.3 & 0.0114 & -4.25 \\
\hline 200.1 & $82 \rightarrow 93$ & 90.9 & 120.7 & 0.0054 & -3.31 \\
\hline 199.4 & $73 \rightarrow 83$ & 69.1 & 89.9 & 0.0849 & 0.01 \\
\hline 196.9 & $74 \rightarrow 84$ & 94.9 & 76.2 & 0.0032 & 2.22 \\
\hline 196.5 & $75 \rightarrow 85$ & 88.2 & 128.6 & 0.0128 & -23.6 \\
\hline 194.6 & $81 \rightarrow 89$ & 99.5 & 96.9 & 0.0037 & -1.08 \\
\hline 193.0 & $82 \rightarrow 94$ & 97.3 & 117.7 & 0.0001 & -0.80 \\
\hline 192.7 & $73 \rightarrow 84$ & 86.8 & 80.9 & 0.0184 & 9.82 \\
\hline \multirow[t]{4}{*}{191.1} & $74 \rightarrow 85$ & 25.3 & 81.3 & 0.1171 & 45.29 \\
\hline & $72 \rightarrow 83$ & 16.8 & & & \\
\hline & $77 \rightarrow 86$ & 8.8 & & & \\
\hline & $78 \rightarrow 84$ & 7.1 & & & \\
\hline \multirow[t]{3}{*}{191.0} & $72 \rightarrow 83$ & 42.8 & 110.7 & 0.0615 & -59.97 \\
\hline & $82 \rightarrow 95$ & 19.4 & & & \\
\hline & $77 \rightarrow 86$ & 6.7 & & & \\
\hline 190.5 & $82 \rightarrow 95$ & 75.4 & 80.1 & 0.0615 & -59.97 \\
\hline 190.1 & $82 \rightarrow 96$ & 93.6 & 130.9 & 0.0123 & 7.88 \\
\hline \multirow[t]{2}{*}{190.0} & $80 \rightarrow 87$ & 53.3 & 43.8 & 0.0047 & -6.88 \\
\hline & $74 \rightarrow 85$ & 26.7 & & & \\
\hline \multirow[t]{5}{*}{189.1} & $74 \rightarrow 85$ & 29.0 & 93.5 & 0.0072 & 14.87 \\
\hline & $80 \rightarrow 87$ & 14.4 & & & \\
\hline & $73 \rightarrow 85$ & 9.4 & & & \\
\hline & $79 \rightarrow 84$ & 8.5 & & & \\
\hline & $80 \rightarrow 85$ & 7.4 & & & \\
\hline \multirow[t]{4}{*}{188.5} & $77 \rightarrow 86$ & 25.3 & 96.8 & 0.2308 & -29.21 \\
\hline & $80 \rightarrow 87$ & 16.8 & & & \\
\hline & $76 \rightarrow 86$ & 13.3 & & & \\
\hline & $72 \rightarrow 83$ & 12.6 & & & \\
\hline \multirow[t]{6}{*}{188.0} & $78 \rightarrow 85$ & 16.7 & 91.5 & 0.2123 & -8.75 \\
\hline & $79 \rightarrow 85$ & 10.8 & & & \\
\hline & $79 \rightarrow 87$ & 9.8 & & & \\
\hline & $81 \rightarrow 90$ & 9.0 & & & \\
\hline & $80 \rightarrow 84$ & 8.9 & & & \\
\hline & $78 \rightarrow 84$ & 5.9 & & & \\
\hline 187.6 & $81 \rightarrow 90$ & 86.2 & 105.8 & 0.0152 & -16.12 \\
\hline
\end{tabular}

ther thank Mrs. C. Vermeeren for her technical assistance.

[4] E. Fischer and Y. Hirshberg, J. Chem. Soc. 1952, 4522.

[5] Y. Hirshberg, J. Amer. Chem. Soc. 78, 2304 (1956).

[6] G. Bercovic, V. Krongauz, and V. Weiss, Chem. Rev. 100, 1741 (2000).

[7] S. Kawata and Y. Kawata, Chem. Rev. 100, 1777 (2000).

[8] B. L. Feringa, R. A. van Delden, N. Koumura, and E. D. Geertsema, Chem. Rev. 100, 1789 (2000). 
[9] J. A. Delaire and K. Nakatani, Chem. Rev. 100, 1817 (2000).

[10] N. Tamai and H. Miyasaka, Chem. Rev. 100, 1875 (2000).

[11] H. Rau, Chem. Rev. 83, 535 (1983).

[12] B. Stephan, A. Mannschreck, N. A. Voloshin, N. V. Volbushko, and V.I. Minkin, Tetrahedron Lett. 31, 6335 (1990).

[13] R. Kiesswetter, N. Pustet, F. Brandl, and A. Mannschreck, Tetrahedron: Asym. 10, 4677 (1999).

[14] L. Loncar-Tomaskovic, K. Lorenz, A. HergoldBrundic, D. Mrvos-Sermec, A. Nagl, M. Mintas, and A. Mannschreck, Chirality 11, 363 (1999).

[15] J. A. Pople, and D. L. Beveridge, Approximate Molecular Orbital Theory, McGraw-Hill Book Company, New York 1970, p. 11.
[16] R. Ahlrichs, In: Encyclopedia of Computational Chemistry. P. v. R. Schleyer, Ed. TURBOMOLE, Wiley, Chichester 1998, Vol. 5, pp. 3123-3129.

[17] A. D. Becke, Phys. Rev. A. 5, 3098 (1988); J. P. Perdew, Phys. Rev. B. 33, 8822 (1986).

[18] A. Klamt, and G. Schüürmann, J. Chem. Soc., Perkin Trans. 2, 799 (1993).

[19] F. Furche, R. Ahlrichs, C. Wachsmann, E. Weber, A. Sobanski, F. Vögtle, and S. Grimme, J. Amer. Chem. Soc. 122, 1717 (2000).

[20] A. Moscowitz, in O. Sinanoglu (ed.), Modern Quantum Chemistry, John Wiley \& Sons, Inc., New York 1965, Vol. 3, p. 21.

[21] J. A. Schellman, Chem. Rev. 75, 323 (1975).

[22] G. Kurapkat, P. Krüger, A. Wollmer, J. Fleischhauer, B. Kramer, E. Zobel, A. Koslowski, and R. W. Woody, Biopolymers 41, 267 (1997).

[23] E. Keller, Chem. Unserer Z. 20, 178 (1986). 